\title{
Analysis of the influence of the heating process on the charring depth of wooden elements
}

\author{
Andrzej Marciniak, ${ }^{1, *}$ \\ ${ }^{1}$ The Main School of Fire Service, Faculty of Fire Safety Engineering, 52/54 Slowackiego St., 01-629 \\ Warsaw, Poland
}

\begin{abstract}
In accordance with European standards in the field of designing wooden structures in the design process and in fire safety engineering, differentiated fire impacts should be applied, depending on the expected scenario of its development. These interactions describe the time-temperature relationship. Fire resistance is generally related to the thermal interaction determined by a logarithmic relationship called a standard curve describing a fire developed in a room in the form. It is possible to use other, more realistic scenarios characterizing the thermal impact determined by the so-called nominal curves covering the effects of fire emanating from a window or hydrocarbon fires (eg in fuel depots). Individual fire scenarios can also be used. The basis for determining the time to the loss of the load bearing capacity of the wooden structure (fire resistance due to the load capacity criterion for a given temperature course over time) is the geometric characteristics of the uncut core of the crosssection. The dimensions of the uncut, working cross section are determined so far only for rods heated according to the standard curve, assuming a charring speed for glued laminated timber of $0.50-0.80 \mathrm{~mm} / \mathrm{min}$ depending on the type of wood and product. For other curves, research in this area is lacking.
\end{abstract}

\section{Introduction}

The building should be designed and constructed in such a way that during the fire it fulfills certain functions defined by postulative requirements, the level of which is determined by the relevant regulations, namely:

1. Load capacity should be provided for a limited time.2. The possibility of spreading fire and smoke in the building should be limited.

3. The possibility of fire spreading to neighboring buildings should be limited.

4. Users must be able to evacuate.

5. The safety of rescue teams should be taken into account.

Providing the load-bearing capacity of a building structure during a fire is a basic requirement. Without meeting this condition, it is difficult to talk about meeting other fire safety conditions.

\footnotetext{
* Corresponding author: amarciniak@sgsp.edu.pl
} 
Requirements for the building elements and the products from which they were made depend on the specific thermal interactions and assumed functions that should be met in fire conditions. According to Eurocode No. 1 - Actions on Structures. Part 1-2 in fire safety engineering should use differentiated fire impacts, depending on the expected scenario of its development. These interactions describe the time-temperature relationship.

Fire resistance is generally related to the thermal interaction determined by a logarithmic relationship called a standard curve describing a fire developed in a room in the form of:

$$
\Theta g=345 \log (8 t+1)+20
$$

where:

$\Theta g$ - gas temperature in the furnace, ${ }^{\circ} \mathrm{C}$,

$t$ - duration of thermal exposure during the fire test, min.

It is possible to use other, more realistic scenarios characterizing the thermal impact determined by the so-called nominal curves covering the effects of fire emanating from a window or hydrocarbon fires (eg in fuel depots). Individual fire scenarios can also be used. In the case of wooden structures, the fire temperature can affect the elements directly or indirectly through the cladding.

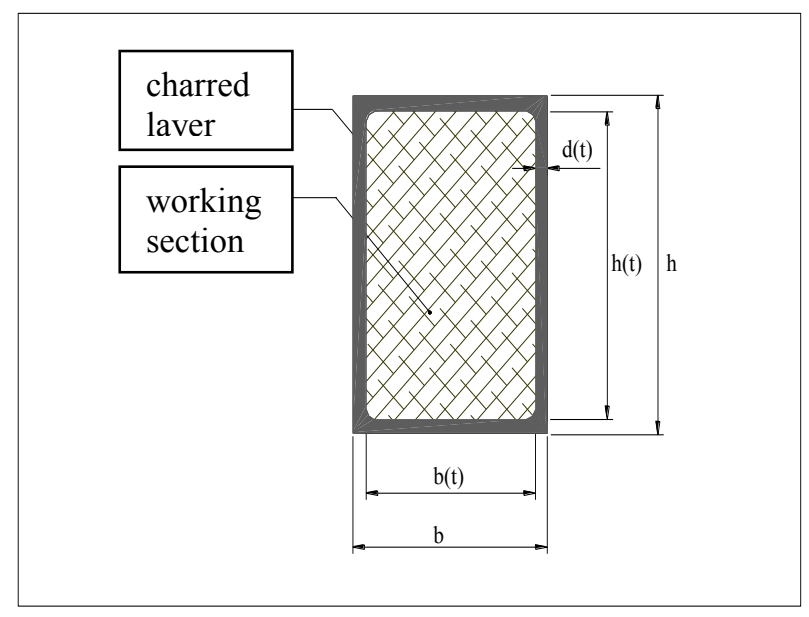

Fig. 1. Working cross section of a wooden element during a fire.

High temperature causes charring of wood. The carbonized layer (d) fulfills the function of insulation to some extent. Its strength properties are negligible. The load is transmitted through the uncut core of the cross-section. The basis for determining the time to the loss of the load bearing capacity of the wooden structure (fire resistance due to the load capacity criterion for a given temperature course over time) is the geometric characteristics of the uncut core of the cross-section. The dimensions of the uncropped working cross section are currently determined only for bars heated according to the standard curve, assuming a charring speed for glued laminated timber of $0.50-0.80 \mathrm{~mm} /$ min depending on the type of wood and product [2].

For other curves we do not have such dependencies. Therefore, it is not possible to assess the bearing capacity of wooden structures in case of fire scenarios determined individually. This is a significant obstacle in the use of fire safety engineering methods to assess the load capacity of wooden rod systems. 


\section{Assumptions of the model accepted for research}

It has been assumed that the characteristic that covers various heating processes is the amount of heat reaching the boundary surface, i.e. the area defined by the isotherm $\Theta=\Theta z$, where $\Theta z$ - the beginning temperature of charring.

It was assumed that the heat flow reaching the boundary surface surrounded by charred wood and caused by different heat sources is the same as the apparent heat flow transmitted by radiation reaching the boundary surface without taking into account the processes occurring in the char as well as the insulation of this layer. If we assume that thermal radiation decides about the course of charring, then the apparent heat flow transmitted by radiation, resulting from the exchange between the environment and the boundary surface, can be written as a dependence:

$$
h_{n}=h_{n}^{r}
$$

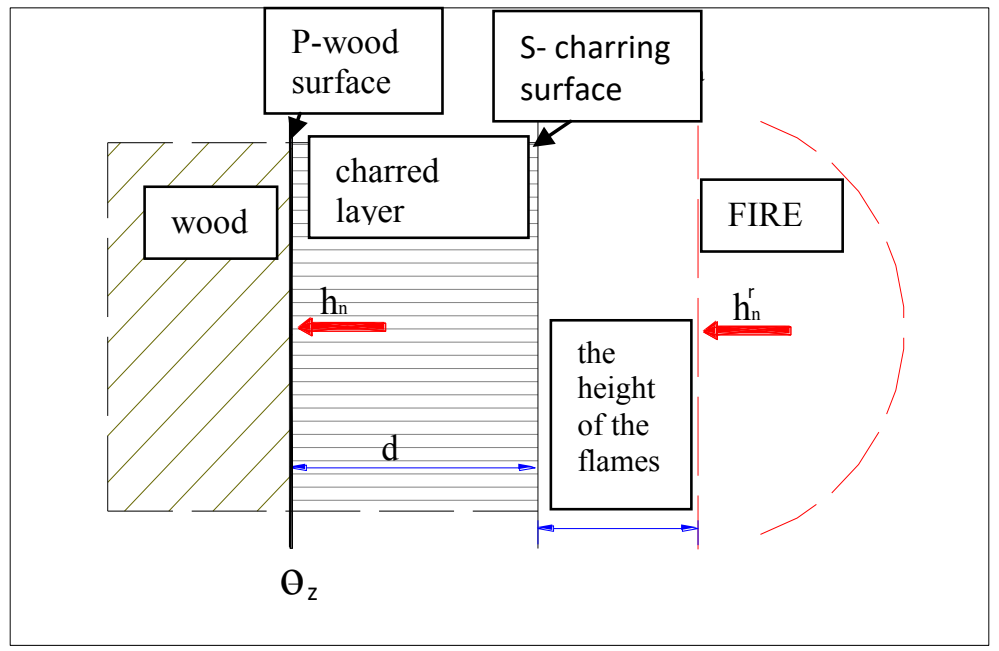

Fig. 2. Diagram of the energy balance of the heated section.

The Stefan - Boltzmann law was used to describe the density of heat flux through radiation.

If by $\varepsilon_{s}$ and $\varepsilon_{f}$ we denote the emissivity of the carbon layer and the flames, we can assume that:

$\varepsilon_{s}=0.9$ for the heated wood surface (we assume that the surface of the wood changes in color at the carbonizing temperature $\Theta z$ ),

$\varepsilon_{f}=0.8$ for the hot gas zone.

The resulting emissivity can be saved as:

$$
\varepsilon_{\text {res }}=\varepsilon_{s} \cdot \varepsilon_{f}
$$

Then, the apparent heat flux entering the surface of the beginning of charring can be determined from the dependence:

$$
h_{n}^{r}=\phi \varepsilon_{r e s} \cdot 5,67 \cdot 10^{-8}\left[\left(\Theta_{p}+273\right)^{4}-\left(\Theta_{e}+273\right)^{4}\right]\left[\mathrm{kW} / \mathrm{m}^{2}\right]
$$

where:

$\phi$ - coefficient of configuration, the value was equal to 1 , because it was assumed that the 
radiating surface is geometrically equal to the receiving surface (heated surface of the test element)

$\Theta p$ - temperature of the hot gas layer,

$\Theta e$ - temperature of the beginning of charring,

$5.67 * 10-8$ - Stefan-Boltzmann's constant.

Assuming that the charring depth $\mathrm{d}$ will be a function of the amount of $E c$ heat that has reached the boundary surface at time $t-t_{o}\left(t_{o}\right.$ - time to reach the charring temperature on the wood surface), we can write:

$$
d=f\left[E_{c}(t)\right],
$$

where:

$$
E_{c}(t)=\int_{t-t_{0}}^{t} h_{n}^{r}(t) d t
$$

\subsection{Determination of charring temperature $(\Theta z)$}

It was assumed that the charring process begins if the wood in the cross-section under consideration reaches the temperature $(\Theta z)$. As the beginning of the charring process, the change in the surface color, which corresponds to the temperature value $\Theta z$, was assumed. Therefore, to calculate the thermal energy reaching the considered depth of the research element, it was assumed that the carbonization process began when: $\Theta e=\Theta z$

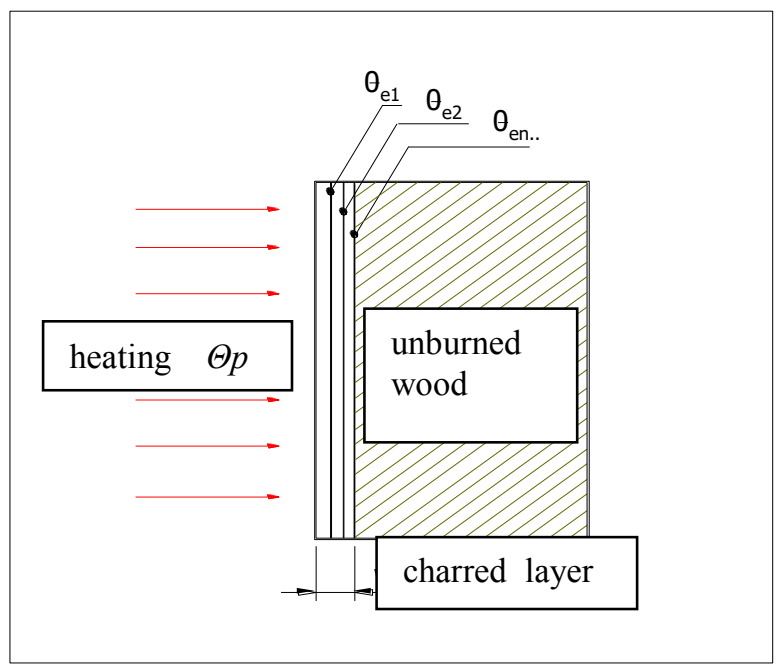

Fig. 3. Determining the charring temperature $\Theta z$.

where:

$\Theta e$ - temperature of the test element at a given measuring point,

$$
\Theta e 1=\Theta e 2=\Theta e n=\Theta z \text { - the beginning of charring }
$$




\subsection{Determining the depth of charring}

Determining changes in the depth of charring in time based on direct measurement of the charcoal layer thickness is very difficult, since the measurement requires different intervals of time to interrupt the heating process and to stop the flameless burning that takes place in the charred layer.

In connection with the above, this measurement would be burdened with a significant error and very difficult to implement. Therefore, it was assumed that the course of the charring process will be considered on the basis of the temperature distribution inside the tested element assuming that (according to equation 8), in the given cross-section of the research element the carbonization process started when it reached the temperature $\Theta z$.

\section{Research program}

The research elements were made of large-size elements made of glued laminated spruce, which are used in the construction industry as bar elements such as girders, arches, purlins, bolts and columns.

The glued elements are made of spruce timber of at least C 27 class according to EN 338. Board thickness $33-45 \mathrm{~mm}$. Glue melamine was used for gluing. Samples for determination of charring temperature were made of sections from the above wood with dimensions of $15 \mathrm{~cm} \times 15 \mathrm{~cm} . \times 5 \mathrm{~cm}$. However, the dimensions of the research elements to determine the depth of charring were $90 \mathrm{~cm}$ x $90 \mathrm{~cm}$ x $20 \mathrm{~cm}$. Before starting the tests, the elements were stored in a closed and roofed room (isolated from atmospheric influences) and were in the same temperature and humidity conditions.

The research program included:

1. Determining the carbonization temperature $\Theta z$ - (setting the temperature of the wood in which the carbonization process of the test material begins). A test used in the analysis of the temperature distribution to determine the point (surface) of the carbonization start in the research element.

2. Appointment of charring depth based on the temperature distribution. The research elements were heat-dried according to three time-temperature curves, namely according to the curve: No. 1 - a relatively slow increase in temperature over time, curve No. 2 - similar to the curve previously used in fire resistance tests and curve No. 3 - with sharp increase in temperature in the unit time.

As the standard heating curves, temperature changes over time varied in severity, namely:

- for curve 1 , the reference relationship described in the following equation is assumed [1]:

$$
\Theta g=660[1-0.687 \exp (-0.32 t)-0.331 \exp (-3.8 t)]+20
$$

- for curve 2 , the reference relationship describes the equation (1)

$$
\Theta g=345 \log (8 t+1)+20
$$

- for curve 3, the reference relationship was adopted in accordance with the following equation:

$$
\Theta g=1080[1-0.325 \exp (-0.1667 t)-0.675 \exp (-2.5 t)]+2
$$

where:

$\Theta g$ - gas temperature in the furnace,

$t$ - warm up time. 


\section{Results and analysis of tests}

\subsection{Results of the carbonization test $\Theta z$}

Based on the observation of the change in the color of the surface of the test sample, changes were found informing about the beginning of the charring process in the temperature range $228-234^{\circ} \mathrm{C}$ (depending on the position of the measurement point).

On the basis of the conducted tests, it was assumed that the beginning of the charring process begins at the temperature $\Theta z=230^{\circ} \mathrm{C}$. It was assumed that this temperature is a limit determinant of the beginning of the formation of a charred layer at specific points of the cross section of the research element.

The above experiment was repeated three times and similar temperature values were obtained. The value of the $\Theta z=230{ }^{\circ} \mathrm{C}$ temperature determined in the tests corresponds to the temperature values of the beginning of charring, which is given in the literature [3].

\subsection{The results of the charring depth test}

Heating was performed according to the following three curves: curve 1, curve 2 and curve 3 (in accordance with assumptions described in the research program). The following graphs show the change in mean, actual heating temperature for all three cases along with the course of the standard heating curves described by equations (9); (1); (10).

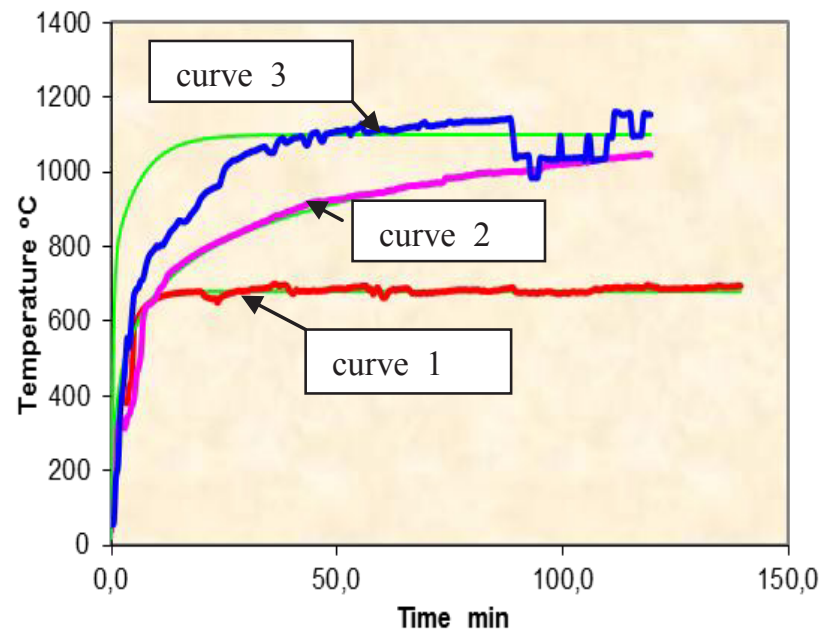

Fig.4. Change in the average real heating temperature of the research element in time (oven furnace) for individual heat curves.

\section{Analysis of test results}

Based on temperature changes over time and based on dependence (4), the apparent density of heat flux was calculated, which flows to the heated section.

$$
h_{n}^{r}=\phi \varepsilon_{\text {res }} \cdot 5,67 \cdot 10^{-8}\left[\left(\Theta_{p}+273\right)^{4}-\left(\Theta_{e}+273\right)^{4}\right]\left[\mathrm{kW} / \mathrm{m}^{2}\right]
$$

Energy Ec was calculated based on the change in apparent heat flux over time using equation (11): 


$$
E_{c}=\int_{0}^{t_{n}} h_{n}^{r}(t) d t
$$

Using the relationship (12) Ec energy was calculated which is necessary to start the carbonization process at the considered depth $(d)$.

$$
E_{c}=\int_{0}^{t_{d}} h_{n}^{r}(t) d t
$$

where: $t d$ - time corresponding to the beginning of charring at a given point (at a given depth) of the cross-section of the research element ( $\mathrm{d}-5,10,15,20,25,30,35,40 \mathrm{~mm}$ - for both measuring bases)

The results of calculations are shown in Fig.5.

The calculated mean values were approximated by the linear function of the form:

$$
d=1,3 \cdot 10^{-4} E_{c}
$$

where:

$E c$ - energy entering the considered cross-section

$\left[\mathrm{MJ} / \mathrm{m}^{2}\right]$,

$d$ - charring depth $[\mathrm{m}]$.

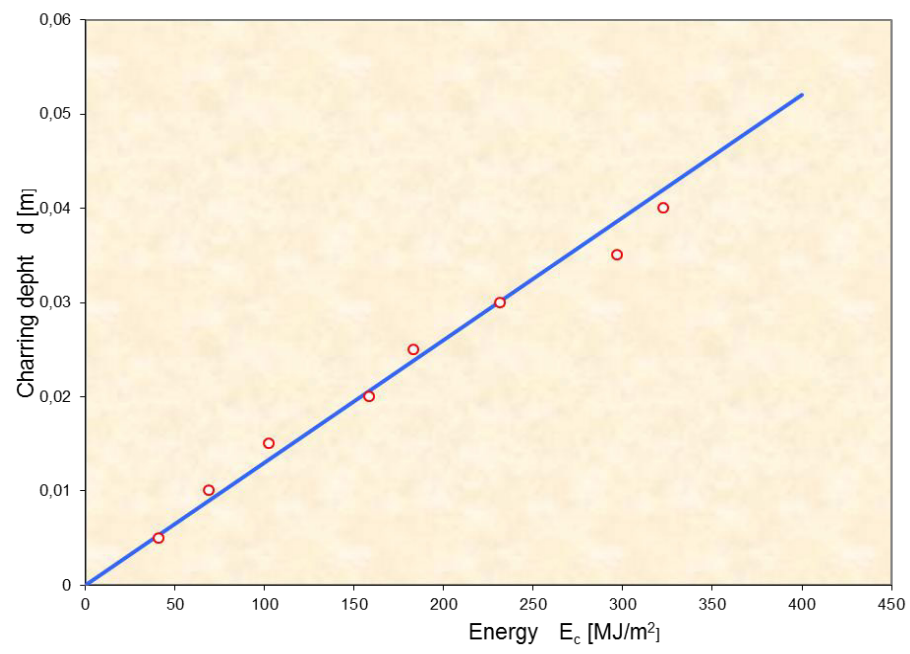

Fig.5. Simple regression of Ec values depending on the depth charring d.

The average standard deviation is 2.83. The correlation coefficient between the Ec values and char depth $\mathrm{d}$ is 0.99 .

The value of the calculated coefficient indicates that the dependence used well approximates the test results. 


\section{Conclusions}

1. The research issue consisting in the formulation and experimental verification of the adopted model allowing to determine the depth of charring of glued wood depending on the temperature course.

2. The adopted model of direct heat exchange between the flue gas and the boundary surface, i.e. the surface of the beginning of charring of the wooden section, was verified experimentally. Verification was carried out for the most commonly used spruce, glued laminated timber.

3. An empirical relationship was obtained between the apparent amount of heat supplied to the boundary surface as a result of radiation and the depth of charring with a correlation coefficient of 0.99 .

4. For a given relationship describing the temperature rise of the fire developed over time, the apparent amount of heat supplied to the boundary surface determined by the $230{ }^{\circ} \mathrm{C}$ isotherm is unambiguously related to time. In connection with the above, the empirical dependence allows to determine the depth of charring after a given heating time for a defined time-temperature relationship.

5. The obtained dependence can be used to determine the geometrical dimensions of the unburnt, load-bearing of the cross-section, with almost-dependencies describing the increase in temperature over time, characterizing the various developed fire scenarios.

6. It allows to calculate the fire resistance of glued timber construction due to the criterion of load capacity (fire resistance) not only for a standard fire, determined by the standard curve but also by other time-temperature dependencies.

\section{References}

1. Eurocode 1, Actions on Structures. Part 1-2: General Actions - Actions on structures exposed to fire

2. Eurocode 5 - Design of timber structures. Part 1-2: General rules - Structural fire design

3. R. White, E.V. Nordheim, Fire Techn. 28, (1992) 